\title{
Numerical investigation of local defectiveness control of diblock copolymer patterns
}

\author{
D. Jeong, Y. Choi, J. Kim] $]^{*}$ \\ Department of Mathematics, Korea University, Seoul 136-713, Republic of Korea
}

Received October 21, 2015, in final form December 22, 2015

\begin{abstract}
We numerically investigate local defectiveness control of self-assembled diblock copolymer patterns through appropriate substrate design. We use a nonlocal Cahn-Hilliard $(\mathrm{CH})$ equation for the phase separation dynamics of diblock copolymers. We discretize the nonlocal $\mathrm{CH}$ equation by an unconditionally stable finite difference scheme on a tapered trench design and, in particular, we use Dirichlet, Neumann, and periodic boundary conditions. The value at the Dirichlet boundary comes from an energy-minimizing equilibrium lamellar profile. We solve the resulting discrete equations using a Gauss-Seidel iterative method. We perform various numerical experiments such as effects of channel width, channel length, and angle on the phase separation dynamics. The simulation results are consistent with the previous experimental observations.
\end{abstract}

Key words: diblock copolymer, nonlocal Cahn-Hilliard equation, local defectivity control

PACS: $02.60 . C b, 02.60 . L j, 02.70 . B f, 02.70 . P t$

\section{Introduction}

A diblock copolymer is a linear chain consisting of two blocks of different types of monomers bonded covalently to each other. The two blocks are mixed above the critical temperature; however, the copolymer melt undergoes phase separation below the critical temperature due to the incompatibility of different blocks [1]. As a result of phase separation, periodic structures including lamellae [2-7], spheres [2, 3, 8, 12], cylinders [2, 3, 6, 10, 13, 14], hexagons [2, 3, 7, 10, 13, 17], and gyroids [2, 3, 10] are observed in a mesoscopic-scale domain.
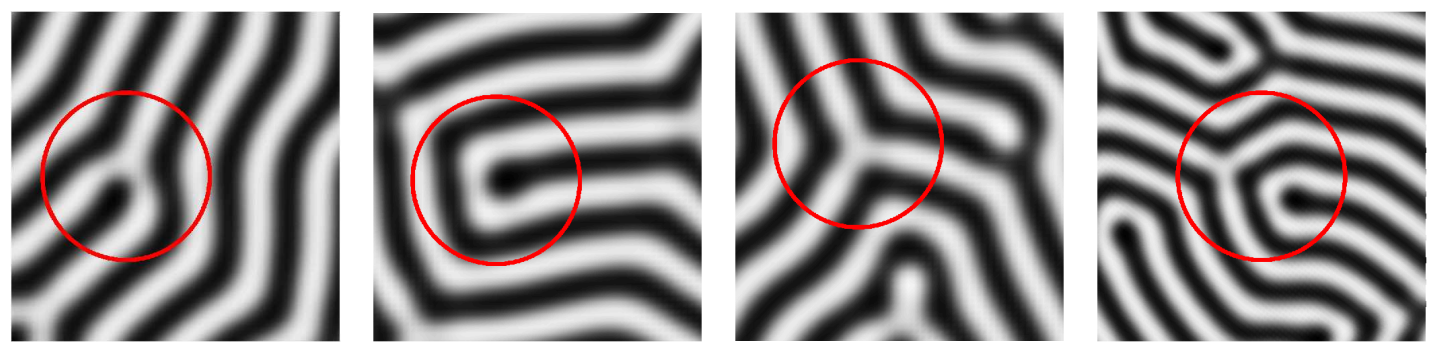

Figure 1. Examples of local defects.

In recent years, self-assembly of block copolymer has come out as a promising patterning tool to overcome the scaling limits in nano-lithography and generate suboptical lithographic patterns [18]. However, one of the problems is the lack of complete pattern orientation due to a high density of defects [19]. In figure 1. we can observe various examples of local defect in the block copolymer. Therefore, it is very important to control the local defects of self-assembled polymer patterns with the application of these materials. As the efforts to rectify this, many researches and techniques such as electric fields [20], flow

\footnotetext{
${ }^{*}$ Corresponding author, E-mail: cfdkim@korea.ac.kr.
} 
[21], shear application [22-24], thermal treatment [25], chemically pre-patterned surface (chemoepitaxy) [26. 27], and topographical confinement (graphoepitaxy) [28] have been carried out to reduce the defect density in specific pattern-forming block copolymer thin films. Among the controlling method, authors in [19] proposed an appropriate substrate design and achieved a defect-free pattern formation. In this paper, we focus on numerically realizing the situation presented in [19] and we describe in detail the numerical method which is used in the numerical simulations.

We use the mathematical model proposed by Ohta and Kawasaki [29]. Let $\phi$ be the difference of the local volume fraction of $A$ and $B$ monomers. Then, the nonlocal Cahn-Hilliard (CH) equation in a twodimensional domain is

$$
\begin{aligned}
\frac{\partial \phi(\mathbf{x}, t)}{\partial t} & =\Delta \mu(\mathbf{x}, t)-\alpha[\phi(\mathbf{x}, t)-\bar{\phi}] \\
\mu(\mathbf{x}, t) & =F^{\prime}(\phi(\mathbf{x}, t))-\epsilon^{2} \Delta \phi(\mathbf{x}, t)
\end{aligned}
$$

where $\mathbf{x}=(x, y)$ and $t$ are the spatial and temporal variables, respectively. $F(\phi)=0.25\left(\phi^{2}-1\right)^{2}$ is the Helmholtz free energy, $\epsilon$ is the gradient energy coefficient, $\alpha$ is inversely proportional to the square of the total chain length of the copolymer, and $\bar{\phi}=\int_{\Omega} \phi(\mathbf{x}, 0) \mathrm{d} \mathbf{x} /|\Omega|$ is the average concentration over the domain $\Omega$ [30].

In equation $[1], \alpha[\phi(\mathbf{x}, t)-\bar{\phi}]$ term indicates the long-range interaction and plays an important part in pattern formation. If $\alpha=0$, then equations (1) and (2) describe the process of the reduction in the total interfacial energy of a microstructure as the classical $\mathrm{CH}$ equation.

The total system energy is given as

$$
\mathscr{E}(\phi)=\int_{\Omega}\left[F(\phi)+\frac{\epsilon^{2}}{2}|\nabla \phi|^{2}\right] \mathrm{d} \mathbf{x}+\frac{\alpha}{2} \int_{\Omega} \int_{\Omega} G(\mathbf{x}-\mathbf{y})[\phi(\mathbf{x})-\bar{\phi}][\phi(\mathbf{y})-\bar{\phi}] \mathrm{d} \mathbf{y} \mathrm{d} \mathbf{x},
$$

where $G$ is the Green's function of $-\Delta$ in $\Omega$ with periodic boundary conditions, i.e., $-\Delta G(\mathbf{x})=\delta(\mathbf{x})$. Then, the evolving equations (1) and (2) can be derived using the $H^{-1}$ gradient flow for the free energy (3), and equation (3) can be rewritten as

$$
\mathscr{E}(\phi)=\int_{\Omega}\left[F(\phi)+\frac{\epsilon^{2}}{2}|\nabla \phi|^{2}\right] \mathrm{d} \mathbf{x}+\frac{\alpha}{2} \int_{\Omega}|\nabla \psi|^{2} \mathrm{~d} \mathbf{x}
$$

where $\psi$ satisfies $-\Delta \psi=\phi-\bar{\phi}$ with periodic boundary conditions [2].

Now, we will solve equations (1) and (2) on a trench domain. Figure 2 represents the physical domain $(\Omega)$ and boundaries $\left(\Gamma_{1}, \Gamma_{2}\right)$. On $\Gamma_{1}$, Dirichlet boundary condition for $\phi$ and homogeneous Neumann boundary condition for $\mu$ are used. On $\Gamma_{2}$, the periodic boundary condition for both $\phi$ and $\mu$ is used.

The rest of this paper is organized as follows. In section 2. we describe the numerical method and solution. In section 3 we present several numerical experiments. Conclusions are summarized in section 4.

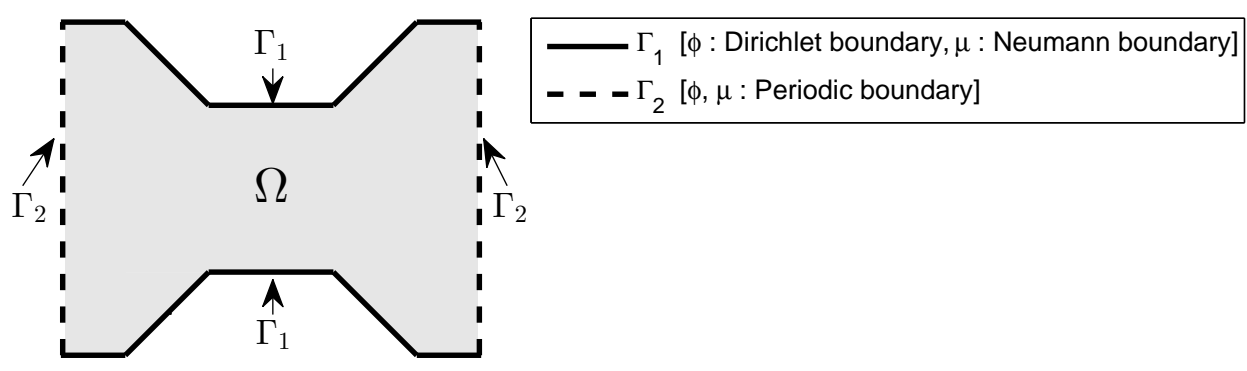

Figure 2. Illustration of the physical domain $(\Omega)$ with boundaries $\Gamma_{1}$ and $\Gamma_{2}$. 


\section{Numerical method}

\subsection{Discretization of domain}

First, assume that we have a domain $\Omega$ as shown in figure 2 The domain $\Omega$ is defined by the angle $\theta$, reference values $a$ and $b$ for the trench wall as represented in figure 3 Here, the trench walls are determined with symmetric points $(-a, b),(a, b),(-a,-b)$, and $(a,-b)$. Then, we cover the domain $\Omega$ by a rectangular domain $\Omega_{\mathrm{R}}=\left(-L_{x}, L_{x}\right) \times\left(-L_{y}, L_{y}\right)$ with a Cartesian grid of mesh size $h$.

Now, we discretize the rectangular domain $\Omega_{\mathrm{R}}$ with the uniform mesh size $h=2 L_{x} / N_{x}=2 L_{y} / N_{y}$ in both $x$ - and $y$-directions. Here, $N_{x}$ and $N_{y}$ are the number of grid points in $x$ - and $y$-directions, respectively. We denote cell-corner points as $\left(x_{i}, y_{j}\right)=\left(h_{i}, h_{j}\right)$ for $i=0, \ldots, N_{x}$ and $j=0, \ldots, N_{y}$. Let $\phi_{i j}^{n}$ and $\mu_{i j}^{n}$ be approximations of $\phi\left(x_{i}, y_{j}, t_{n}\right)$ and $\mu\left(x_{i}, y_{j}, t_{n}\right)$, respectively, where $t_{n}=n \Delta t$ and $\Delta t$ is the temporal step size.

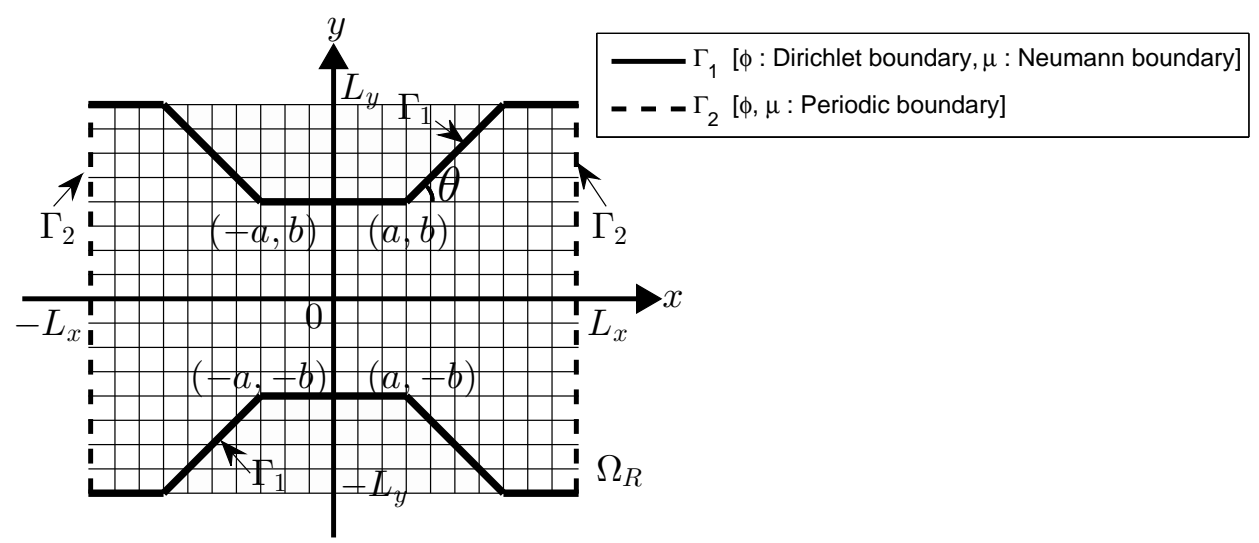

Figure 3. Illustration of the parameters over the whole domain $\Omega_{\mathrm{R}}=\left(-L_{x}, L_{x}\right) \times\left(-L_{y}, L_{y}\right) . \Gamma_{1}$ and $\Gamma_{2}$ are boundary of the computational domain which is determined from $\theta$. Trench walls are defined with symmetric points $(-a, b),(a, b),(-a,-b)$, and $(a,-b)$.

\subsection{Numerical solution}

In this paper, we apply a non-linearly stabilized splitting scheme [31] to the nonlocal $\mathrm{CH}$ equations (1) and (2) as follows:

$$
\begin{aligned}
\frac{\phi_{i j}^{n+1}-\phi_{i j}^{n}}{\Delta t} & =\Delta_{h} \mu_{i j}^{n+1}-\alpha\left(\phi_{i j}^{n+1}-\bar{\phi}\right), \\
\mu_{i j}^{n+1} & =\left(\phi_{i j}^{n+1}\right)^{3}-\phi_{i j}^{n}-\epsilon^{2} \Delta_{h} \phi_{i j}^{n+1},
\end{aligned}
$$

where $\bar{\phi}=\sum_{\mathbf{x}_{i j} \in \Omega_{h}} \phi_{i j}^{0} / \sum_{\mathbf{x}_{i j} \in \Omega_{h}} 1$. Here, $\Omega_{h}$ is the computational domain which is represented by marked circle in figure 4

To solve equations (4) and (5), we use the Gauss-Seidel iterative method. Given solution $\phi_{i j}^{n}$, let $\phi_{i j}^{n+1,0}=\phi_{i j}^{n}$ be an initial guess. For each $m \geqslant 0$, we generate the updated solution $\phi_{i j}^{n+1, m+1}$ and $\mu_{i j}^{n+1, m+1}$ from $\phi_{i j}^{n+1, m}$ and $\mu_{i j}^{n+1, m}$ by

$$
\left(\frac{1}{\Delta t}+\alpha\right) \phi_{i j}^{n+1, m+1}+\frac{4}{h^{2}} \mu_{i j}^{n+1, m+1}=\frac{\phi_{i j}^{n}}{\Delta t}+\alpha \bar{\phi}+\frac{\mu_{i-1, j}^{n+1, m+1}+\mu_{i+1, j}^{n+1, m}+\mu_{i, j-1}^{n+1, m+1}+\mu_{i, j+1}^{n+1, m}}{h^{2}},
$$




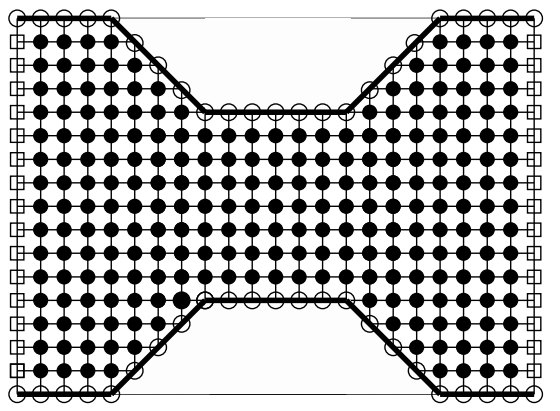

$\begin{array}{ll}O & \phi: \text { Dirichlet boundary, } \mu: \text { Neumann boundary } \\ \text { - Interior domain } \Omega_{\mathrm{h}} \\ \square & \text { Periodic boundary }\end{array}$

Figure 4. Inner grid points (•) which are on the computational domain $\Omega_{h}$, Dirichlet $(\phi)$ and homogeneous Neumann $(\mu)$ boundary points ( $($ ), and periodic boundary points $(\square)$.

$$
\begin{aligned}
{\left[-\frac{4 \epsilon^{2}}{h^{2}}-3\left(\phi_{i j}^{n+1, m}\right)^{2}\right] \phi_{i j}^{n+1, m+1}+\mu_{i j}^{n+1, m+1}=} & -\phi_{i j}^{n}-2\left(\phi_{i j}^{n+1, m}\right)^{3} \\
& -\epsilon^{2} \frac{\phi_{i-1, j}^{n+1, m+1}+\phi_{i+1, j}^{n+1, m}+\phi_{i, j-1}^{n+1, m+1}+\phi_{i, j+1}^{n+1, m}}{h^{2}}
\end{aligned}
$$

We continue the above iterations until $l_{2}$-norm error between two successive approximations of $\phi$ is less than a given tolerance tol, that is,

$$
\left\|\phi^{n+1, m+1}-\phi^{n+1, m}\right\|_{2}<\text { tol. }
$$

\subsection{Boundary conditions}

For a numerical solution, we consider three different conditions at each boundary as follows:

- $\phi_{i j}=\left\|\phi^{\mathrm{eq}}\right\|_{\infty}$ for $\mathbf{x}_{i j} \in \Gamma_{1}$.

- $\nabla_{h} \mu_{i j}=0$ for $\mathbf{x}_{i j} \in \Gamma_{1}$.

- $\phi_{0 j}=\phi_{N_{x}+1, j}$ and $\mu_{0 j}=\mu_{N_{x}+1, j}$ for $j=1, \ldots, N_{y}+1$.

Here, $\left\|\phi^{\mathrm{eq}}\right\|_{\infty}$ represents the maximum value of numerical solution at equilibrium state. In subsection 2.4 we will describe more details for $\left\|\phi^{\mathrm{eq}}\right\|_{\infty}$.

Near the boundaries, we should use some special formulae. For example, let us consider the position $\left(x_{i}, y_{j}\right)$ in figure 5 . By the Dirichlet boundary condition, we already know the value at $A$ and $B$. We define

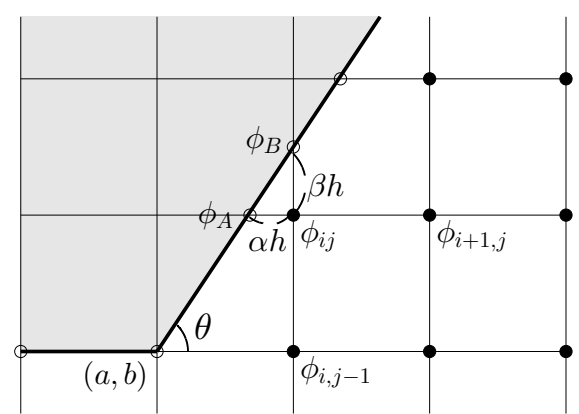

(a)

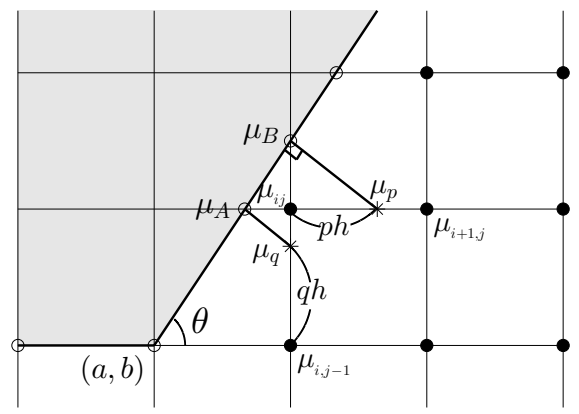

(b)

Figure 5. (a) Dirichlet condition and (b) Neumann condition on curved boundary. 
$\Delta_{x x}^{\mathrm{D}}$ and $\Delta_{y y}^{\mathrm{D}}$ as the discrete second derivatives near the boundary as follows:

$$
\begin{aligned}
\Delta_{x x}^{\mathrm{D}} \phi_{i j} & =\left(\frac{\phi_{i+1, j}-\phi_{i j}}{h}-\frac{\phi_{i j}-\phi_{A}}{\alpha h}\right)\left(\frac{\alpha h+h}{2}\right)^{-1}, \\
\Delta_{y y}^{\mathrm{D}} \phi_{i j} & =\left(\frac{\phi_{B}-\phi_{i j}}{\beta h}-\frac{\phi_{i j}-\phi_{i, j-1}}{h}\right)\left(\frac{\beta h+h}{2}\right)^{-1},
\end{aligned}
$$

where $0<\alpha, \beta<1$, and $\phi_{A}=\phi_{B}=\left\|\phi^{\mathrm{eq}}\right\|_{\infty}$. Therefore, the discrete Laplacian operator near the boundary with Dirichlet condition is defined as $\Delta_{h}^{\mathrm{D}} \phi_{i j}^{n+1}=\Delta_{x x}^{\mathrm{D}} \phi_{i j}^{n+1}+\Delta_{y y}^{\mathrm{D}} \phi_{i j}^{n+1}$. For other points, the discrete Laplacian is similarly defined. We also define the discrete Laplacian operator near the boundary with Neumann boundary condition as $\Delta_{h}^{\mathrm{N}} \mu_{i j}^{n+1}=\Delta_{x x}^{\mathrm{N}} \mu_{i j}^{n+1}+\Delta_{y y}^{\mathrm{N}} \mu_{i j}^{n+1}$. Here,

$$
\begin{aligned}
& \Delta_{x x}^{\mathrm{N}} \mu_{i j}=\left(\frac{\mu_{i+1, j}-\mu_{i j}}{h}-\frac{\mu_{i j}-\mu_{q}}{\alpha h}\right)\left(\frac{\alpha h+h}{2}\right)^{-1}, \\
& \Delta_{y y}^{\mathrm{N}} \mu_{i j}=\left(\frac{\mu_{p}-\mu_{i j}}{\beta h}-\frac{\mu_{i j}-\mu_{i, j-1}}{h}\right)\left(\frac{\beta h+h}{2}\right)^{-1},
\end{aligned}
$$

where $\alpha$ and $\beta$ are defined as in figure 5(a). $\mu_{p}$ and $\mu_{q}$ are obtained by using a linear interpolation, $\mu_{p}=p \mu_{i+1, j}+(1-p) \mu_{i j}$ and $\mu_{q}=q \mu_{i j}+(1-q) \mu_{i, j-1}$ [see figure 5(b)].

\subsection{Optimal wavelength having minimum discrete total energy}

We describe an algorithm for finding the total energy-minimizing wavelength [1. 4]. We define the optimal wavelength $L^{*}$ as the period of the hexagonal lattice that has the lowest energy. In other words, $L^{*}$ means the smallest length having the global minimum of the domain-scaled discrete total energy. To calculate $L^{*}$, we solve equations (1) and (2) until a numerical equilibrium state is reached with the given values of $h_{x}, \Delta t, \epsilon$, and $\alpha$. The initial condition is $\phi(x, 0)=0.1 \cos \left(2 \pi x / L_{x}\right)$ in $\Omega=\left(0, L_{x}\right)$, where $L_{x}$ starts at $2 h_{x}$ and increases in steps of $2 h_{x}$. Let $M$ be the smallest even integer such that the domainscaled total energy $\mathscr{E} \mathrm{d} / L_{x}$ is minimized. Construct the quadratic polynomial passing the three points $\left((M-2) h_{x}, \mathscr{E}^{\mathrm{d}} /\left[(M-2) h_{x}\right]\right),\left(M h_{x}, \mathscr{E}^{\mathrm{d}} /\left(M h_{x}\right)\right)$, and $\left((M+2) h_{x}, \mathscr{E} \mathrm{d} /\left[(M+2) h_{x}\right]\right)$; then, define the optimal length $L^{*}$ as the critical point of the polynomial [see figure 6 (a)]. For more details, see references [1 4].

We define the numerical equilibrium state as that in which the consecutive error is not larger than the prescribed tolerance, that is, $\max _{1 \leqslant i \leqslant N_{x}}\left(\left|\phi_{i}^{k+1}-\phi_{i}^{k}\right|\right) / \Delta t \leqslant 1.0 \times 10^{-6}$. The maximum value of equilibrium wave is defined as $\left\|\phi^{\mathrm{eq}}\right\|_{\infty}=\max _{1 \leqslant i \leqslant N_{x}}\left|\phi_{i}^{\mathrm{eq}}\right|$ in figure $6(\mathrm{~b})$.

We replace the Dirichlet problem solution with $\left\|\phi^{\mathrm{eq}}\right\|_{\infty}$ in this paper.

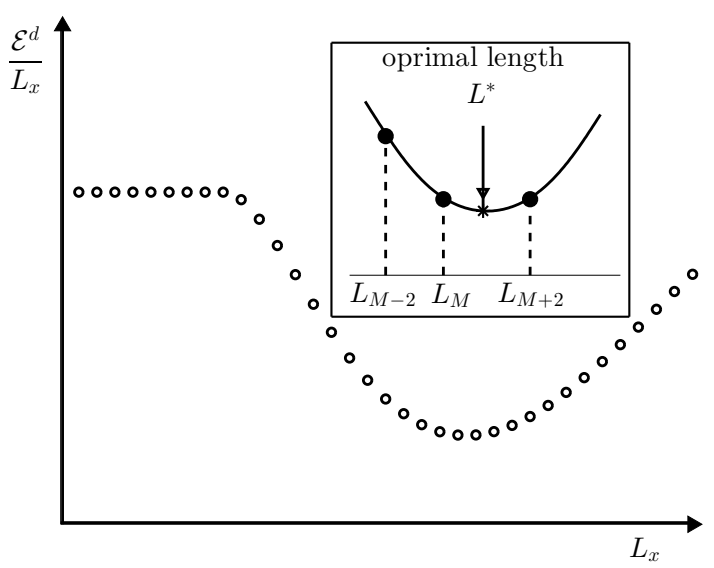

(a)

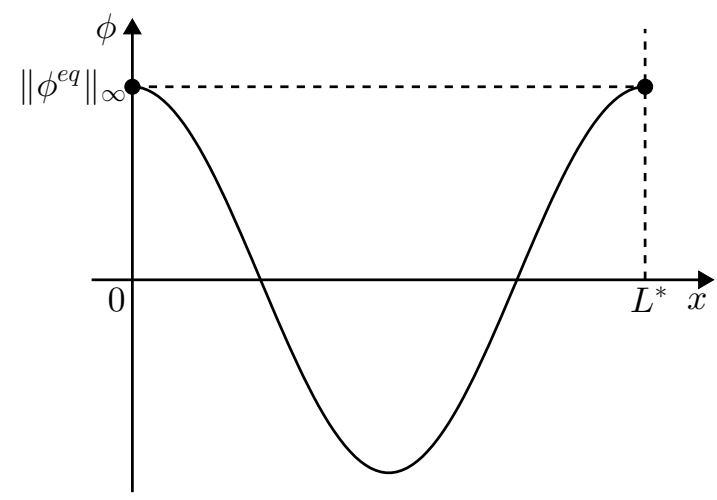

(b)

Figure 6. (a) Schematic of algorithm to search for the optimal length $L^{*}$. Here, $L_{M-2}=(M-2) h_{x}, L_{M}=$ $M h_{x}$, and $L_{M+2}=(M+2) h_{x}$. (b) Illustration of maximum value $\left\|\phi^{\mathrm{eq}}\right\|_{\infty}$ of equilibrium wave. 


\section{Numerical experiments}

In this section, we perform a number of numerical tests. Throughout the numerical experiments, unless otherwise specified, we use $\epsilon=1 /(20 \sqrt{2}), \alpha=100, L^{*}=0.375, h=L^{*} / 10, \Delta t=0.1 h,\left\|\phi^{\mathrm{eq}}\right\|_{\infty}=$ 0.6134 , and $\theta=\pi / 4$. We examine the evolution of a random perturbation about the average concentration $\bar{\phi}=0$ on simple rectangle domain $\Omega_{\mathrm{R}}=\left(-25 L^{*}, 25 L^{*}\right) \times\left(-15 L^{*}, 15 L^{*}\right)$ with $N_{x}=500, N_{y}=300$. The initial condition is set to $\phi(x, y, 0)=\bar{\phi}+0.01 \operatorname{rand}(x, y)$. Here, $\operatorname{rand}(x, y)$ is a random number between -1 and 1 . Also, we use tol $=10^{-4}$ for stopping criterion of the Gauss-Seidel iteration.

\subsection{Discrete total energy}

We first define the discrete total energy as

$$
\begin{aligned}
\mathscr{E}^{\mathrm{d}}\left(\phi^{n}\right)=\sum_{i=1}^{N_{x}} \sum_{j=1}^{N_{y}}\{ & h^{2} F\left(\phi_{i j}^{n}\right)+\frac{\epsilon^{2}}{2}\left[\left(\phi_{i+1, j}^{n}-\phi_{i j}^{n}\right)^{2}+\left(\phi_{i, j+1}^{n}-\phi_{i j}^{n}\right)^{2}\right] \\
+ & \left.\frac{\alpha}{2}\left[\left(\psi_{i+1, j}^{n}-\psi_{i j}^{n}\right)^{2}+\left(\psi_{i, j+1}^{n}-\psi_{i j}^{n}\right)^{2}\right]\right\}
\end{aligned}
$$

Note that $\psi$ satisfies $-\Delta \psi=\phi-\bar{\phi}$ with periodic boundary conditions [2].

Figure 7 shows the temporal evolution of the normalized discrete total energy $\mathscr{E}^{\mathrm{d}}\left(\phi^{n}\right) / \mathscr{E}^{\mathrm{d}}\left(\phi^{0}\right)$. In figure 7. we can see that the normalized discrete total energy (which is denoted by the solid line) is nonincreasing as time proceeds. Moreover, the four small figures represent the numerical solution at times $t=30 \Delta t, 100 \Delta t, 700 \Delta t, 2000 \Delta t$, respectively.

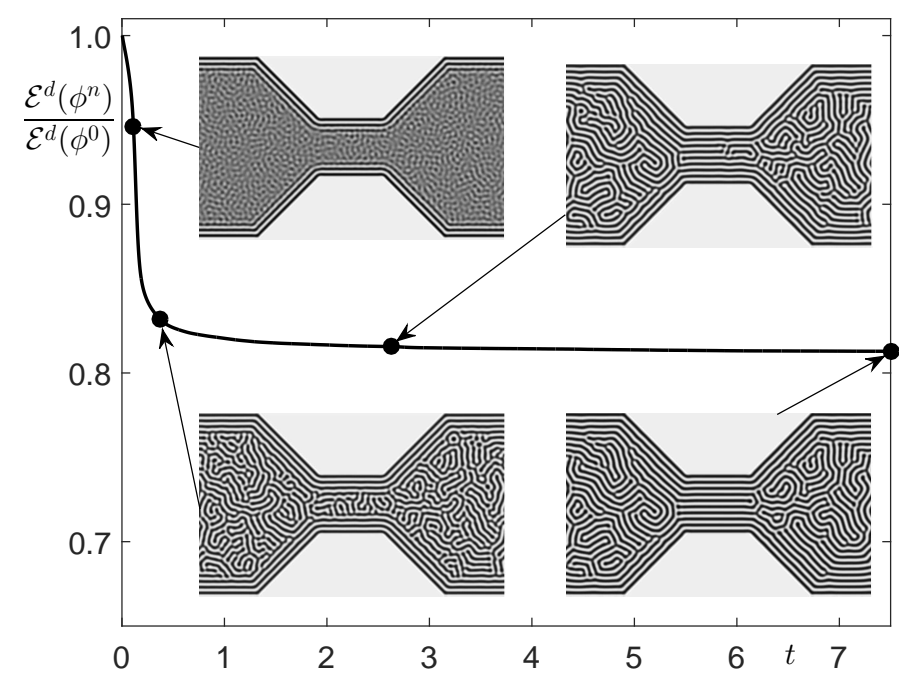

Figure 7. Time evolution of the normalized discrete total energy $\mathscr{E}^{\mathrm{d}}\left(\phi^{n}\right) / \mathscr{E}^{\mathscr{d}}\left(\phi^{0}\right)$. Here, the small figures indicate the concentration field $\phi$ at times $t=30 \Delta t, 100 \Delta t, 700 \Delta t, 2000 \Delta t$, respectively.

\subsection{The effect of channel width}

To investigate the effect of the channel width, we fix $a=5 L^{*}$ with $b=2 L^{*}$ and $b=5 L^{*}$. Figures 8 (a) and (b) show the temporal evolution of $\phi$ with the trench widths $2 b=4 L^{*}$ and $2 b=10 L^{*}$, respectively. We can observe that the self-assembled pattern is completely defect-free and is aligned parallel to the trench walls within the narrow trench area; all the defects reside in the wider regions on either side, which is consistent with the experimental results [19]. 
(a)

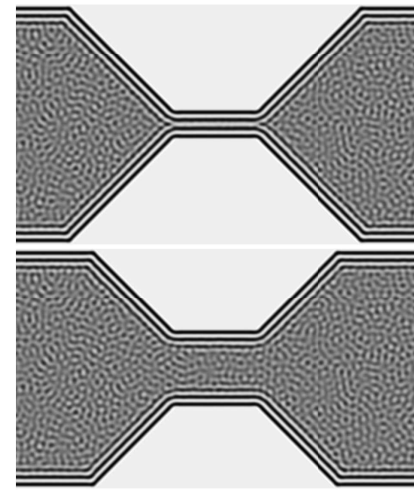

$t=30 \Delta t$

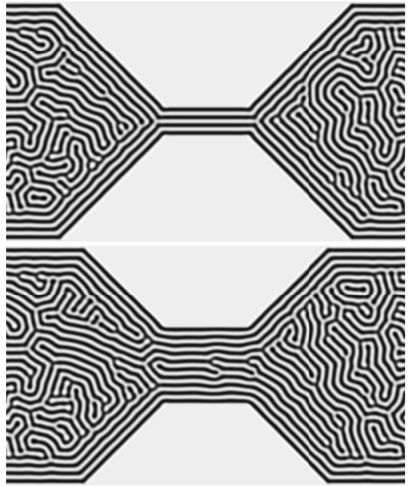

$t=100 \Delta t$

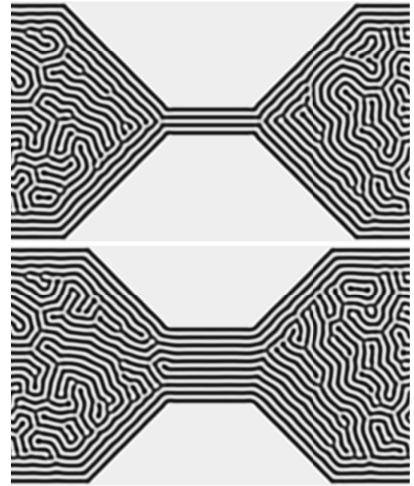

$t=2000 \Delta t$

Figure 8. The effect of different trench width: (a) $4 L^{*}$ and (b) $10 L^{*}$. Evolution times are given below each figure.

\subsection{The effect of channel length}

In this section, we simulate two cases with respect to a narrow channel length. For this test, we use two different values $a=4.5 L^{*}$ and $a=9 L^{*}$ when we fix $b=4.5 L^{*}$. The numerical results can be seen in figure 9 Similarly to the previous tests, we can see that the numerical solution in the narrow channel has the defect-free lamella pattern.

(a)

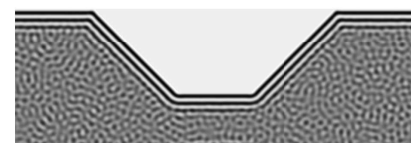

(b)

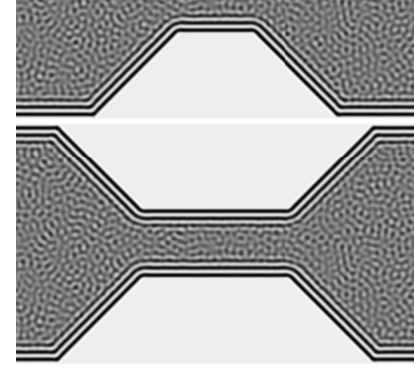

$t=30 \Delta t$

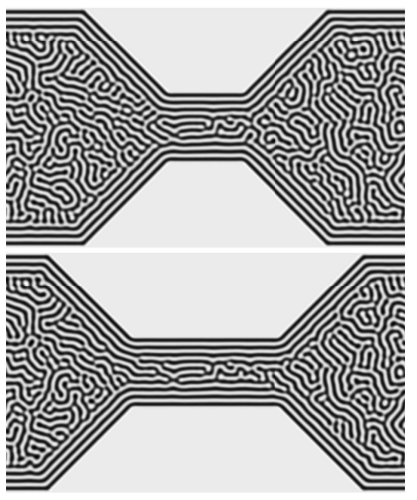

$t=100 \Delta t$

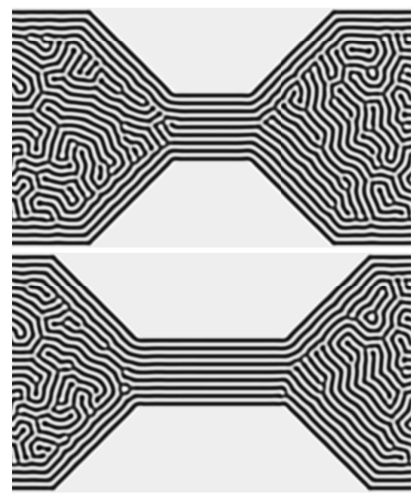

$t=2000 \Delta t$

Figure 9. The effect of different trench length: (a) $9 L^{*}$ and (b) $18 L^{*}$. Evolution times are given below each figure.

\subsection{The effect of angle}

To see the dynamics of the angle, we only change the angle as $\theta=\pi / 3, \pi / 4$, and $\pi / 6$ with $a=b=5 L^{*}$. Figure 10 represents the temporal evolution of pattern formation in channels with respect to the angle. In all three cases, we observe that the numerical solution in the narrow channel has aligned lamella patterns parallel to the trench walls. Also, within the narrow trench region, the self-assembled pattern is defect-free unlike the side region where all the defects are located.

Figure 11 shows the profiles of $\phi$ at equilibrium state for each $\epsilon=0.02,0.03$, and 0.04 .

From the result in figure 11 as $\epsilon$ value is increasing, we observe that the amplitude of $\phi$ is smaller and the wavelength is wider. 
(a)

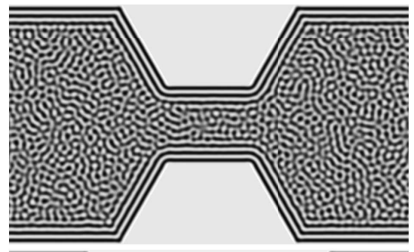

(b)

(c)

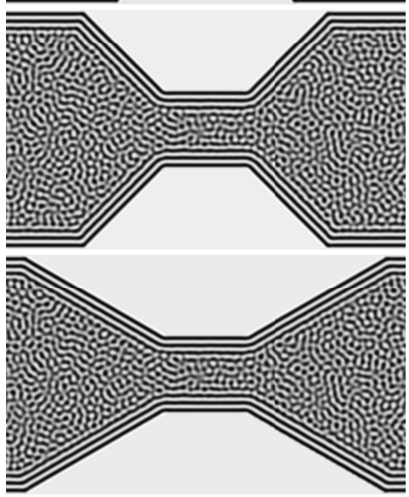

$t=40 \Delta t$
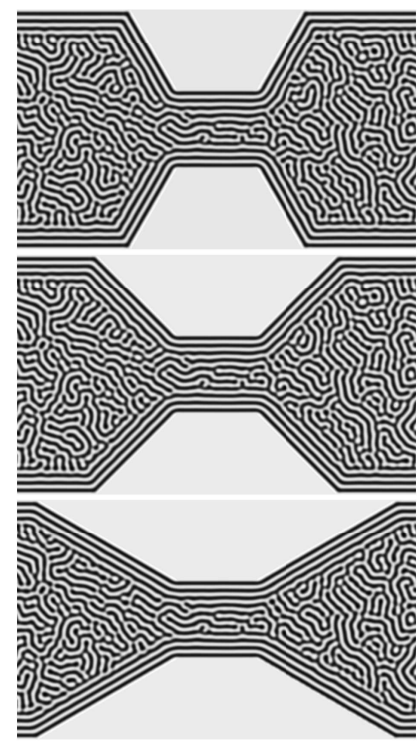

$t=100 \Delta t$
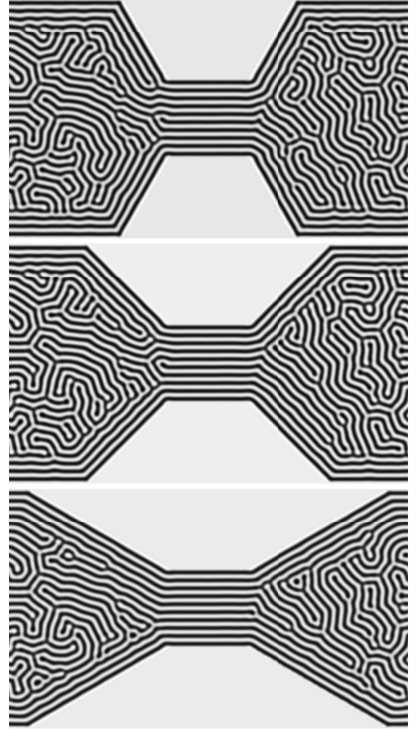

$t=2000 \Delta t$

Figure 10. The effect of the angle: (a) $\theta=\pi / 3$, (b) $\pi / 4$, and (c) $\pi / 6$. Evolution times are given below each figure.

\subsection{Comparison of Dirichlet and Neumann boundary conditions}

In this section, we compare numerical results by the Dirichlet and Neumann boundary conditions. We have the comparison test on the same geometry shown in figure 10 (c). Figure 12 (a) shows the temporal evolution of $\phi$ when applying Dirichlet and homogeneous Neumann conditions for $\phi$ and $\mu$ on the boundary $\Gamma_{1}$, respectively. Figure 12 (b) represents the temporal evolution of $\phi$ when applying homogeneous Neumann condition for $\phi$ and $\mu$ on the boundary $\Gamma_{1}$. As we expected, we obtain the lamella pattern in the narrow channel when we apply the Dirichlet boundary condition on $\Gamma_{1}$. However, the numerical solution with the zero homogeneous boundary condition for $\phi$ has many defects in the narrow channel and a contact angle of $90^{\circ}$ on all boundaries.

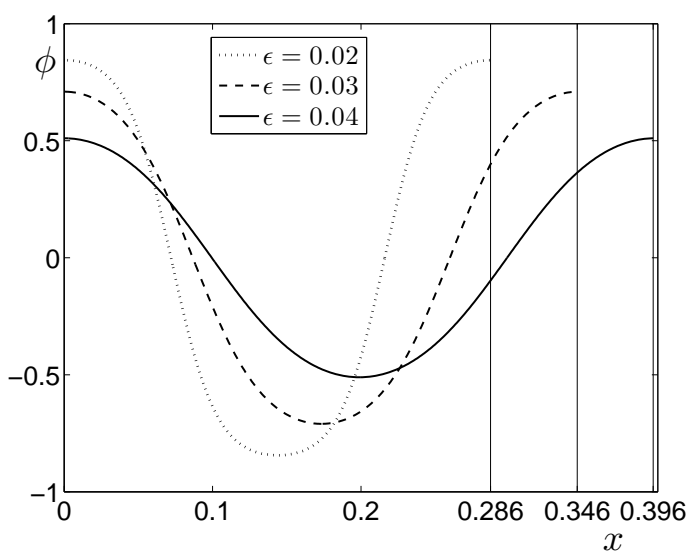

Figure 11. Profiles of $\phi$ at the equilibrium state when $\epsilon=0.02,0.03$, and 0.04 . We reprinted from [35], with permission from the Current Applied Physics. 
(a)

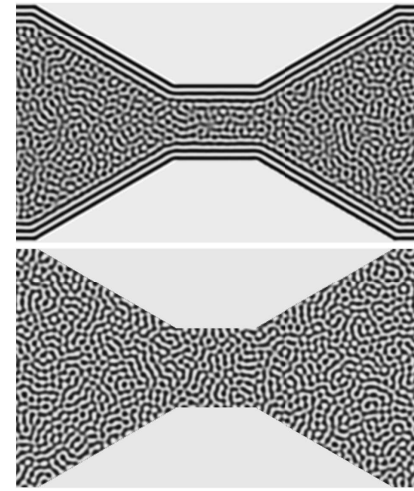

$t=40 \Delta t$

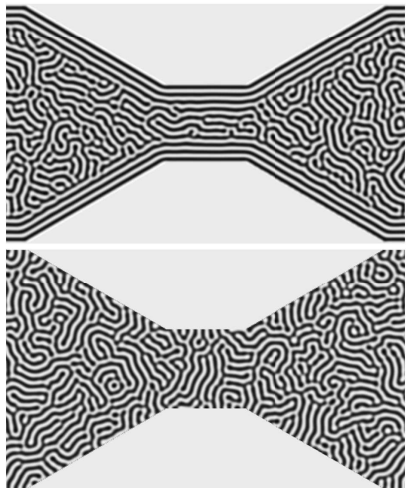

$t=100 \Delta t$

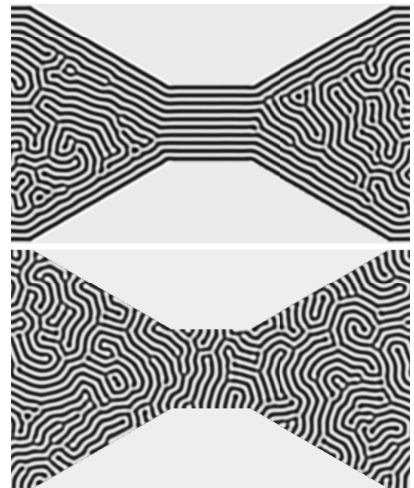

$t=2000 \Delta t$

Figure 12. Time evolution of $\phi$ when applying (a) the Dirichlet and (b) the homogeneous Neumann boundary condition for $\phi$ on $\Gamma_{1}$. The other boundary conditions are used to be equal to the previous examples. Here, we denote the simulation time on the bottom of figures columns line.

\section{Conclusions}

In this paper, we numerically investigated the local defectiveness control of self-assembled diblock copolymer patterns through appropriate substrate design. We used a nonlocal Cahn-Hilliard equation for the phase separation dynamics of diblock copolymers. We discretized the nonlocal $\mathrm{CH}$ equation by an unconditionally stable finite difference scheme on a tapered trench design and, in particular, we used Dirichlet, Neumann, and periodic boundary conditions. The value at the Dirichlet boundary is obtained from energy-minimizing wavelength. We solved the resulting discrete equations using the Gauss-Seidel iterative method. We performed various numerical experiments to know the effect of the channel width, length, and angle. Our simulation results were consistent with real experimental observations.

\section{Acknowledgement}

The first author (D. Jeong) was supported by a Korea University Grant. The corresponding author (J.S. Kim) was supported by the National Research Foundation of Korea (NRF) grant funded by the Korea government (MSIP) (NRF-2014R1A2A2A01003683).

\section{References}

1. Jeong D., Lee S., Choi Y., Kim J., Curr. Appl. Phys., 2015, 15, 799; doi 10.1016/j.cap.2015.04.033

2. Choksi R., Peletier M.A., Williams J.F., SIAM J. Appl. Math., 2009, 69, 1712; doi $10.1137 / 080728809$

3. Fink Y., Urbas A.M., Bawendi M.G., Joannopoulos J.D., Thomas E.L., J. Lightwave Technol., 1999, 17, 1963; doi $10.1109 / 50.802981$.

4. Jeong D., Shin J., Li Y., Choi Y., Jung J.H., Lee S., Kim J., Curr. Appl. Phys., 2014, 14, 1263; doi 10.1016/j.cap.2014.06.016

5. Lee M., Cho B.K., Kim H., Yoon J.Y., Zin W.C., J. Am. Chem. Soc., 1998, 120, 9168; doi 10.1021/ja980654w

6. Spencer R.K.W., Wickham R.A., Soft Matter, 2013, 9, 3373; doi 10.1039/C3SM27499C.

7. Yokojima Y., Shiwa Y., Phys. Rev. E, 2002, 65, 056308; doi 10.1103/PhysRevE.65.056308

8. Gao J., Tang P., Yang Y., Soft Matter, 2013, 9, 69; doi 10.1039/C2SM26758F.

9. Kim T., Son S.K., Lee D.K., Ko M.J., Kim K., Curr. Appl. Phys., 2010, 10, 189; doi 10.1016/j.cap.2010.08.035

10. Lin B., Zhang H., Tang P., Qiu F., Yang Y., Soft Matter, 2011, 7, 10076; doi 10.1039/C1SM06204B

11. Yu Y., Tsai C., Curr. Appl. Phys., 2013, 13, 1128; doi 10.1016/j.cap.2013.03.003.

12. Zhang W., Dong G., Yang H., Sun J., Zhou J., Wang J., Colloid. Surface. A, 2009, 348, 45; doi $10.1016 /$ j.colsurfa.2009.06.029

13. Jackson E.A., Hillmyer M.A., ACS Nano, 2010, 4, 3548; doi 10.1021/nn1014006 
14. Park S., Lee D.H., Xu J., Kim B., Hong S.W., Jeong U., Xu T., Russell T.P., Science, 2009, 323, 1030; doi $10.1126 /$ science. 1168108

15. Li S., Jiang Y., Chen J.Z.Y., Soft Matter, 2014, 10, 8932; doi 10.1039/c4sm01884b

16. Müller M., Sun D.W., J. Phys.: Condens. Matter, 2015, 27, 194101; doi 10.1088/0953-8984/27/19/194101

17. Pál E., Oszkó A., Mela P., Möller M., Dékány I., Colloid. Surface. A, 2008, 331, 213; doi 10.1016/j.colsurfa.2008.08.015

18. Kim B., Laachi N., Delaney K.T., Carilli M., Kramer E.J., Fredrickson G.H., J. Appl. Polym. Sci., 2014, 131, 40790; doi 10.1002/app.40790

19. Ruiz R., Ruiz N., Zhang Y., Sandstrom R.L., Black C.T., Adv. Mater., 2007, 19, 2157; doi 10.1002/adma.200602470

20. Morkved T.L., Lu M., Urbas A.M., Ehrichs E.E., Science, 1996, 273, 931; doi 10.1126/science.273.5277.931.

21. Pelletier V., Adamson D.H., Register R.A., Chaikin P.M., Appl. Phys. Lett., 2007, 90, 163105; doi 10.1063/1.2723673

22. Angelescu D.E., Waller J.H., Adamson D.H., Deshpande P., Chou S.Y., Register R.A., Chaikin P.M., Adv. Mater., 2004, 16, 1736; doi 10.1002/adma.200400643

23. Huber P., J. Phys.: Condens. Matter, 2015, 27, 103102; doi 10.1088/0953-8984/27/10/103102

24. Guo Y., Zhang J., Wang B., Wu H., Sun M., Pan J., Condens. Matter Phys., 2015, 18, 23801; doi $10.5488 /$ CMP.18.23801

25. Sepe A., Hoppe E.T., Jaksch S., Magerl D., Zhong Q., Perlich J., Posselt D., Smilgies D.M., Papadakis C.M., J. Phys.: Condens. Matter, 2011, 23, 254213; doi 10.1088/0953-8984/23/25/254213

26. Kim S.O., Solak H.H., Stoykovich M.P., Ferrier N.J., de Pablo J.J., Nealey P.F., Nature, 2003, 424, 411; doi $10.1038 /$ nature 01775

27. Liu C.C., Ramirez-Hernandez A., Han E., Craig G.S.W., Tada Y., Yoshida H., Kang H.M., Ji S.X., Gopalan P., de Pablo J.J., Nealey P.F., Macromolecules, 2013, 46, 1415; doi 10.1021/ma302464n

28. Segalman R.A., Yokoyama H., Kramerm E.J., Adv. Mater., 2001, 13, 1152; doi 10.1002/1521-4095(200108)13:15<1152::AID-ADMA1152>3.0.CO;2-5

29. Ohta T., Kawasaki K., Macromolecules, 1986, 19, 2621; doi 10.1021/ma00164a028

30. Nishiura Y., Ohnishi I., Physica D, 1995, 85, 31; doi 10.1016/0167-2789(95)00005-O

31. Eyre D.J., Mater. Res. Soc. Symp. Proc., 1998, 529, 39; doi 10.1557/PROC-529-39

32. Hamley I.W., Macromol. Theory Simul., 2000, 9, 363; doi 10.1002/1521-3919(20000801)9:7<363::AID-MATS363>3.0.CO;2-7

33. Choksi R., Ren X., J. Stat. Phys., 2003, 113, 151; doi 10.1023/A:1025722804873

34. Choksi R., Peletier M.A., Williams J.F., SIAM J. Appl. Math., 2009, 69, 1712; doi 10.1137/080728809

35. Jeong D., Shin J., Li Y., Choi Y., Jung J.H., Lee S., Curr. Appl. Phys., 2014, 14, 1263; doi 10.1016/j.cap.2014.06.016

\title{
Числове дослідження керування локальною дефектністю структур діблок-кополімерів
}

\author{
Д. Йонг, Й. Чоі, Ю. Кім \\ Факультет математики, Корейський університет, Сеул 136-713, Республіка Корея
}

Проведено числове дослідження керування локальною дефектністю самоорганізованих структур діблоккополімерів за допомогою відповідної конструкції субстрату. Використовується нелокальне рівняння Кана-Хілларда для динаміки фазового розділення діблок-кополімерів. Здійснено дискретизацію нелокального рівняння з використанням безумовно стійкої схеми скінченної різниці на звуженій канавці зразка і, зокрема, використано крайові умови Діріхле, Ньюмана і періодичні граничні умови. Значення при крайових умовах Діріхле отримано згідно з рівноважним ламеларним профілем, що відповідає енергетичному мінімуму. Ми розв'язуємо отримані дискретні рівняння, використовуючи ітеративний метод ГауссаЗейделя. Проведено різні числові експерименти, такі як вплив ширини каналу, довжини каналу та кута на динаміку фазового розділення. Результати симуляцій відповідають попереднім експериментальним спостереженням.

Ключові слова: діблок-кополімери, нелокальне рівняння Кана-Хілларда, керування локальною дефектністю 